\title{
RETRATO DA ESCOLA NO BRASIL, SEM RETOQUES*
}

\author{
Vera Lucia Sabongi De Rossi*
}

V ma larga moldura preta realça as cores dos girassóis, árvores e pássaros que deslizam no céu azul. A bandeira nacional, imponente, está ondulante. Uma menina à porta da escola, bem vestida, parece suspirar realizada. Será que tentamos achar nas coisas que nos são preciosas o reflexo do que projetou nossa alma? Na verdade, fica difícil distinguir o seu rosto e devassar seus sonhos. Afinal, quem pode recusar-lhe o direito de entregar-se a eles sem obstáculos?

As cores cedem lugar ao branco e preto, quando deixamos para trás a ilustração da capa. Mas os sonhos permanecem nas palavras de Juçara Dutra Vieira, presidente da Confederação Nacional dos Trabalhadores do Brasil (CNTE), na Apresentação do livro - Retrato da escola no Brasil -, organizado por Aída Maria Monteiro Silva e Márcia Ângela da Silva Aguiar: "(...) Nosso desejo é o de construir um novo retrato da escola brasileira. Com o comprometimento de quem faz parte dela. Com a urgência de que a sociedade necessita".

Mesmo o compromisso e a projeção do desejo precisam de uma aliada forte, que hoje parece esquecida - embora no passado fosse considerada parte integrante da retórica -, a prova. Embora Aristóteles na Retórica tenha reagido à imprecisão da palavra pistis (prova), embora exista a linguagem mais modesta de evidence (testemunho), como prefere Perry Anderson e E. P. Thompson (entre outros), Ginzburg prefere a linguagem da prova, por ser a de quem submete os materiais de pesquisa a uma aferição permanente, provando e confirmando, como rezava a famosa divisa da Academia (científica fiorentina) del Cimento. Certa-

* Resenha do livro organizado por Aída Maria Monteiro Silva e Márcia Ângela da Silva Aguiar (Brasília: CNTE, 2004)

** Professora da Faculdade de Educação da Universidade Estadual de Campinas (UNICAMP) e membro do Grupo de Pesquisa “Memória, História e Educação”. E-mail: derossi@mpc.com.br. 
mente caminhamos às apalpadelas, como o luthier que bate delicadamente, com os nós dos dedos, na madeira do violino: uma imagem que Marc Bloch contrapôs à perfeição mecânica do torno, para sublinhar o inextirpável componente artesanal do trabalho do pesquisador (Ginzburg, 2002, p. 13-14). Juçara.

Para perceber a força dos ventos propícios, é importante retomar

Com o nome de Retrato da escola no Brasil, a CNTE tem realizado investigaçôes e produzido análises de dados colhidos por agentes diversos, voltados para a área de educação, bem como por instituições governamentais. A proposta do livro foi a de refletir sobre a contraposição e o cruzamento de fontes documentais extraídas primordialmente da pesquisa Retrato da escola 1 e 2, efetuada nos anos de 2000 e 2001, de autoria do INEP/MEC, que utilizou como base o banco de dados do SAEB, referentes aos anos de 1995, 1997 e 1999.

Ao validar as provas, novamente é a vez de Ginzburg, os pesquisadores deveriam recordar que do ponto de vista da realidade, além de ser intrinsecamente seletivo e parcial, depende de relaçóes de força que condicionam, por meio da possibilidade de acesso à documentação, a imagem total que uma sociedade deixa de si. É preciso levar em conta tanto as relaçôes de força quanto aquilo que é irredutível a elas (idem, ibid., p. 43).

Para a obtenção dos resultados, afirma Juçara, foram feitos seminários com os oito autores dos artigos, que utilizaram outras fontes de pesquisa, o que ampliou a perspectiva analítica inicial e a confrontação de hipóteses. Ginzburg complementa, com toques decisivos:

A idéia de que as fontes, se dignas de fé, oferecem acesso imediato à realidade, ou pelo menos, a um aspecto da realidade, me parece rudimentar. As fontes não são nem janelas escancaradas, como acreditam os positivistas, nem muros que obstruem a visão, como pensam os céticos: no máximo poderíamos compará-las a espelhos deformantes. A análise da distorção específica de qualquer fonte implica já um elemento construtivo. (Ginzburg, op. cit., p. 44)

À primeira vista, o leitor pode estar pensando que o suposto diálogo sobre este tema diz respeito apenas ao pequeno círculo de especialistas: historiadores, filósofos, sociólogos e estudiosos de metodologia. 
Retrato da escola no brasil, sem retoques

Mas esta é uma aparência muito enganosa, explica Ginzburg. A discussão sobre história, retórica e prova, levanta uma questão bastante complexa, implica uma concepção do modo de proceder, que interessa a todos: a convivência e o choque de culturas que permanece cada vez mais dramático e violento, nos dias de hoje, em todo o mundo (idem, ibid., p. 13-14). Na verdade, corremos sérios riscos quando aceitamos a premissa da incompatibilidade entre retórica e prova. Entre eles, encontra-se o da tendência de fragmentar o conhecimento e a vida social numa série de pontos de vista incomunicáveis, nos quais cada grupo se vê murado no interior de sua própria relação com o mundo. $\mathrm{O}$ uso inteligente do contexto faz emergir o anacronismo, escrito com tinta invisivel; em contrapartida, não podemos descartar a capacidade de o gênero humano fazer aparecer e desaparecer a realidade, como se num simples gesto ligasse e desligasse o televisor (idem, ibid., p. 39-43).

Até então, tentei alinhavar os diferentes artigos a partir de uma de suas semelhanças fundamentais, a do compromisso de os autores considerarem criticamente as fontes advindas da base de dados do CNTE e de outras fontes documentais que explicitam ao longo do texto. Agora, pretendo apresentar um breve panorama das diferenças, ou seja, das peculiaridades dos artigos - contidas em seus objetivos principais -, lembrando que o livro certamente merece uma leitura atenta e delicada do público leitor.

Oito autores desdobram diversas temáticas que haviam sido condensadas em cinco relatórios abrangendo questôes sobre infra-estrutura, gestão democrática, trabalhadores em educação, drogas e violência e qualidade da educação.

Carlos Augusto Abicalil, em seu artigo sobre Avaliação, direito e democracia, resgatou o Estado republicano pretendido pela sociedade brasileira, tal como se expressa na Constituição Federal - a educação nacional na perspectiva do direito, de seus princípios e finalidades; a organização formal da educação básica - e apresentou as interfaces entre a herança, a reivindicação e a construção histórica posta por educadores. Caracterizou as bases da reforma educacional imposta e impostora, seus elementos constitutivos, tais como financiamento, formação, carreira currículo, avaliação e gestão.

Luiz Augusto Passos produziu o Retrato bem temperado da cultura escolar brasileira e refletiu sobre as dimensões da cultura na realidade 
escolar brasileira, adentrando no conceito de cultura na tradição grega e moderna e explicitando seu vínculo com a escola. Servindo-se das pesquisas da CNTE - acerca da violência nas escolas - questionou hiatos e limites advindos do perfil sintomático e amostral utilizado pelo MEC.

Luiz Fernandes Dourado, em Gestão democrática da escola: movimentos, tensões e desafios, situou a concepção de gestão presente na área educacional, especialmente o debate sobre o processo de gestão democrática da escola, desencadeado no país. Apresentou a educação como um campo de disputa de projetos e compreende o processo constitutivo e constituinte das relaçóes sociais mais amplas.

Helena Costa Lopes de Freitas escreveu sobre $A$ formação inicial e continuada dos profissionais da educação. Seu artigo traz reflexôes do movimento dos educadores, envolvidos no debate sobre as políticas atuais de formação dos profissionais da educação e também os embates nos planos teórico-práticos presentes que desvelam concepçôes de projetos históricos.

O trabalho dos educadores foi escrito por Maria Isabel de Almeida, com o objetivo de compreender o que está acontecendo com os atuais professores e de colocar em evidência seus objetivos e suas tarefas, para favorecer a sua ação. Discutiu as transformações sociais no contexto do trabalho da escola para entender o conjunto dos problemas escolares como problemas sociais, e vice-versa.

Márcia Ângela da Silva Aguiar, em A reforma da educação básica e as condiçôes materiais das escolas, problematizou as condiçōes materiais, em especial as condiçōes de infra-estrutura, das instituições escolares no âmbito das medidas de política direcionadas à gestão escolar.

Aída Maria Monteiro Silva, em Violência escolar: negação dos direitos humanos e da formação da cidadania, escreveu sobre a violência escolar no sentido de compreender a relação desta com a nãomaterialização dos direitos básicos. Ao investigar como a violência é percebida pelos atores das escolas, alertou sobre alternativas para seu enfrentamento.

Regina Vinhaes Gracindo, em Projeto politico e pedagógico: retrato da escola em movimento, fez uma análise histórica e contextualizada do Ppp, entendendo-o como forma de planejamento no processo de gestão democrática, para a construção de uma escola democrática, de qualidade socialmente referenciada. 
Retrato da escola no brasil, sem retoques

Antes de finalizar, vou destacar mais uma semelhança presente nos artigos, por sinal nada corriqueira na atualidade: a da capacidade propositiva dos autores, ou seja, de abertura de perspectivas teórico-práticas para a formulação de políticas públicas, com potencialidades para alterar o retrato da escola. Seguem algumas das propostas, extraídas aleatoriamente, dos diferentes artigos:

Outro retrato da escola é possível desenhar a partir das lutas sociais em defesa de um projeto de educação pública, gratuita e de qualidade, que leve em conta as necessidades e demandas da sociedade brasileira na contemporaneidade. (Aguiar, p. 137)

Apostar num outro Brasil possível requer uma ação necessária para atuar na denúncia aberta e no anúncio de alternativas socialmente válidas e politicamente sólidas, será necessária uma conduta fundada nos imperativos éticos de resistência. (Abicalil, p. 26)

(...) Estimular a formação de redes múltiplas de experiências (troca de informações entre aquelas unidades escolares com projetos político-pedagógicos similares construídos pela comunidade. (Passos, p. 57)

Pensar a democratização na e da escola implica articular outros mecanismos e participação. Implica, portanto, a construção de um Projeto Político-Pedagógico, a consolidação dos conselhos escolares e grêmios estudantis, a luta pela progressiva autonomia da escola, entre outros mecanismos. (Dourado, p. 78)

O PPP precisa ser democrático (...) com o envolvimento de todos os segmentos da escola: direção professores, funcionários, alunos, pais e comunidade (...). O PPP será o retrato das políticas estabelecidas em nível escolar (...) será o retrato da escola. (Gracindo, p. 174)

Dar proteção aos jovens, professores, pais; manter a infra-estrutura de iluminação perto da escola em bom estado; controlar a venda de bebida alcoólica a menores nas proximidades da escola; controlar e proibir a circulação de drogas ilícitas (...). (Silva, p. 158)

A idéia de desenvolvimento profissional permite redimensionar a prática profissional do professor, colocando-a como resultante da combinaçẫo entre o ensino realizado por ele e sua formação contínua, permeada pelas condiçóes concretas que determinam a ambos (...). (Almeida, p. 116)

O campo da formação de professores está exigindo a definição de uma política global de formação e valorização do magistério que contemple igualmente a formação inicial, as condiçôes de trabalho, a carreira e a formação continuada (...). (Freitas, p. 97) 
Articulação das três esferas públicas para a definição de melhoria das condiçôes físicas materiais das escolas públicas, envolvendo trabalhadores(as) e que levem em consideração as necessidades educacionais efetivas, os interesses e as necessidades da população e os recursos disponíveis. (Aguiar, p. 137)

Há mais um testemunhador bastante atual, embora de longa data, que parece não estranhar boa parte do retrato acima desenhado:

Certas manhãs quando desço do bonde para o centro da cidade, naquelas manhãs em que, no dizer do poeta, um arcanjo se levanta dentro de nós; quando desço do subúrbio, vou vendo, pelo longo do caminho de mais de dez quilômetros, as escolas públicas povoadas. (...) uma grande quantidade de meninas anualmente disputa a entrada na escola normal. (...) procurando com isso aprender para ensinar, o quê? O curso primário, as primeiras letras a meninos e meninas pobres, no que vão gastar sua mocidade, a sua saúde e fanar sua beleza. (...)

Nossa política, que domina nossa edilidade (...) tem por fim fazer a vida incômoda e os povos infelizes e os seus partidos têm por programa um único: não fazer nada de útil. Admiro que os senhores que entendem de instrução pública não digam nada a respeito. (...) pois o remédio, que julgo tão simples, pode não sê-lo; mas espero despertar a atenção dos entendidos e serão eles capazes de achar um bem melhor. Ficarei muito contente e tenho esperança que tal se dê.

Bagatelas (RJ), 3/5/1918, Lima Barreto (1995, p. 13, 18 e 19).

\section{Referências bibliográficas}

GINZBURG, C. Relaçôes de força: história, retórica, prova. São Paulo: Companhia das Letras, 2002.

BARRETO, L. Lima Barreto: crônicas escolhidas. São Paulo: Ática, 1995. 